\title{
The Role of Professional Competency in Influencing Job Satisfaction and Organizational Citizenship
}

\section{Behaviour among Palliative Care Nurses}

\begin{abstract}
OBJECTIVES: It is crucial that palliative care nurses feel competent to practice their profession in accordance with ethical principles, to personalise care, to remain sensitive, to ensure respect, and to communicate effectively. The aim of this study was to verify that higher levels of perceived professional competency predict better individual and organizational outcomes, such as job satisfaction (JS) and organizational citizenship behaviour (OCB).
\end{abstract}

METHOD: An online cross-sectional survey was conducted with 107 Italian palliative care nurses. Structural equation modelling technique was employed for data analysis.

RESULTS: The model fitted the data well: $\chi^{2}=33.50 \mathrm{p}=0.12, \mathrm{CFI}=0.98, \mathrm{TLI}=0.97, \mathrm{RMSEA}=0.06, \mathrm{SRMR}=$ 0.04. Professional competency was positively associated with both JS $(\beta=0.39)$ and OCB $(\beta=0.53)$.

SIGNIFICANCE OF RESULTS: The more confidence palliative care nurses have in their professional competency, the more they are satisfied with their job and engage in OCB. Fostering professional competency in palliative nursing can help not only patients and their families, but also the nurses themselves, the organisation, and their co-workers.

KEYWORDS: Professional competence; Palliative care; Nursing care; Self-efficacy; Work performance 


\section{INTRODUCTION}

Palliative care nurses need to develop specific competencies in order to effectively care for patients during their end-of-life phase and support their families (Sand et al., 2017; Clark et al., 2015). Several scholars focussed on the meaning of the term 'competency' (Fernandez et al., 2012), as well as the identification of the core competencies in palliative nursing care (Becker, 2009; Slatten et al., 2014). According to Parry (1996: 50), a competency is "a cluster of related knowledge, skills, and attitudes that affect a major part of one's job, correlates with performance on the job, can be measured with well accepted standards, and can be improved via training and development". While the European Association for Palliative Care (EAPC) identified the 10 most important skills for clinical practice in palliative care (Gamondi et al., 2013), several profession-specific curricula have emerged at national level. In Italy, the Society for Palliative Care developed the Core Curriculum in Palliative Nursing (SICP, 2013), in line with the needs for health, professionalism, and scientific development.

Although assessing the level of professional competency is crucial, it can represent a challenge, as it requires a multi-perspective and situation-specific approach (Caruso et al., 2016; Reville \& Foxwell, 2017). One of the easiest ways is to use self-report instruments, but self-assessment cannot accurately measure the real level of competency, because of its subjective nature. Nevertheless, the nurses' confidence in their professional competency, that is their self-efficacy beliefs, can play an important role in determining their caring behaviour and clinical choices undertaken, as well as their time and effort invested in their clinical activities. Indeed, the perceived level of professional-competency may hold an intrinsic psychological value and result as a determinant of quality palliative care (Desbiens et al., 2012).

Higher levels of professional competency are associated with greater performance as well as better individual and organizational outcomes (Greenslade \& Jimmieson, 2011). Among individual outcomes, job satisfaction (JS), defined as a positive emotional state resulting from the appraisal of one's job experiences (Locke, 1976), is a fundamental component of work life and can negatively predict nurses' turnover (Galletta et al., 2016). Job satisfaction is influenced by several factors (Caricati et al., 2014), including structural and 
psychological empowerment (Cicolini et al., 2014), but nurses cannot appreciate a job if they do not feel confident to do it effectively, in particular if patients' health is at risk.

Among organizational outcomes, organisational citizenship behaviour (OCB) is increasingly recognised as indicating positive contextual performance (Greenslade \& Jimmieson, 2007; Podsakoff et al., 2009). OCB has been described as those contributions to organisational effectiveness that are neither mandated by own job requirements nor recognised by the formal reward system (Organ, 1988). OCB could be directed towards organisation (civic virtue), or towards co-workers (altruism). Nurses who believe to effectively care for palliative patients might engage more often in $\mathrm{OCB}$, because their confidence in their own role could lead them to act in favour of their colleagues and organization.

Although self-efficacy beliefs, job satisfaction, and extra-role behaviours have been the subject of increasing interest among scholars, to the best of our knowledge, no study has addressed the role of professional competency in predicting JS and OCB in the palliative care context. While scholars reported promising results about the predictive role of self-efficacy (Petitta et al., 2004; Salanova et al., 2011; Walumbwa et al., 2010; Chen \& Kao, 2011; Todd \& Kent, 2006; Ko, 2008), palliative care nurses were the objects of few studies investigating these constructs (Zaghini et al., 2015; Qaseem et al., 2007; Fillion et al., 2009). In this study, we speculate that the more palliative care nurses have confidence in their professional competency, the more they are satisfied with their job and engage in OCB.

\section{METHODS}

\section{Design and Participants}

A cross-sectional correlational study was conducted using on-line data. Participants were palliative care nurses working in hospice and/or at home, from public, non-profit, or private organisations across Italy. All nurses from selected palliative services were invited to participate in on-line survey if they were currently working as staff or head nurses, being contactable via e-mail, and able to read and understand Italian. 


\section{Instruments}

Professional-competency. Participants were asked to self-assess the level of their professional competency using the questionnaire Professional Competency of the Core Curriculum in Palliative Nursing (PC-CCPN) (Prandi et al., 2015). This curriculum includes 26 competencies with associated learning objectives. Among these 26 competencies, a group of experts selected five as the most important (Table 1). They refer to (1) practicing the profession in accordance with ethical principles, (2) personalising the care, (3) remaining sensitive, (4) ensuring respect, and (5) communicating effectively. The PC-CCPN scale includes these five dimensions. The learning objectives described for each competency were adapted into a self-report scale to assess how much nurses believe to be competent in each specific area. The PC-CCPN is a 24-item scale ranging from 0 (not competent at all) to 10 (completely competent), with higher scores indicating greater perceived competency. In the present study, the internal consistency of the scale was $\alpha=0.97$ (Cronbach's alpha).

Job satisfaction. Nurses' JS was assessed using the subscale "job in general" of the Job Descriptive Index (JDI) (Smith et al., 1969). It includes 18 adjectives describing positive and negative aspects of the work experience. Participants can answer using "Y" if they agree, "N" if they disagree and "? " if they are undecided. Scores can range $0-18$, with higher values indicating greater JS. In the present study, internal consistency of the JDI scale was 0.72 (Kuder-Richardson reliability coefficient).

Organizational citizenship behavior $(O C B)$. Self-reported $O C B$ was assessed using the Italian version (Argentero et al., 2008; Zaghini et al., 2015) of the questionnaire by Podsakoff $e t$ al. (1990). It includes 15 items measuring three dimensions: altruism, civic virtue, and conscientiousness. Participants are asked to rate their level of agreement on a 5-point Likert type scale; higher values indicate more OCB. In the present study, internal consistency of the OCB scale was $\alpha=0.87$.

\section{Procedure}

A researcher first emailed a contact person for each selected centre for palliative care. The contact person, who was usually a nurse manager, emailed palliative care nurses working in that centre to ask if they 
wanted to be involved in the survey. This email included the link to the on-line form, whose completion was voluntary and anonymous. The first author received the completed forms for data analysis. Ethics approval to conduct the study was obtained from the University of Rome "Tor Vergata" collaborating to the research.

\section{Data Analysis}

Descriptive statistics (mean, standard deviation [SD], frequencies and percentages) were used to describe the socio-demographic and work characteristics of the sample. Study variables (competency, JS, and OCB) were analysed using means, SDs, and Pearson's correlations. The hypothesised model, examining the role of professional competency in influencing JS and OCB, was tested through structural equation modelling (SEM) technique (Muthén \& Muthén, 1998-2017). Robust maximum likelihood estimator method (MLr) was used to produce standard maximum likelihood parameter estimates with corrected standard errors and chisquare test statistic robust to non-normality and to non-independence of observations (Muthén \& Muthén, 1998-2017). To evaluate the adequacy of the model, the following fit indices were considered: the Comparative Fit Index (CFI; good fit > 0.90), the Tuker and Lewis Index (TLI; good fit >0.90), the Standardized Root Mean Square Residual (SRMR; good fit $\leq$ 0.08), and the Root Mean Square Error of Approximation (RMSEA; good fit < 0.06). Traditional chi-square statistics were also reported (Hu \& Bentler, 1999). Statistical analyses were performed using Mplus 7.1 (Muthén and Muthén, Los Angeles, CA, USA).

\section{RESULTS}

\section{Characteristics of the sample}

A sample of 107 palliative care nurses completed the survey. Participants were mainly females $(\mathrm{n}=90 ; 84.9 \%)$, with a mean age of 42 years ( $\mathrm{SD}=9.6$; range $=24-63)$, and more often married $(\mathrm{n}=74 ; 70 \%)$. Their level of education was university degree for $64 \%(n=69)$ and regional school for $33.7 \%(n=35)$, but only $13.5 \%(n=14)$ of participants completed masters courses in palliative care. Most of them $(n=92 ; 87 \%)$ were working as staff nurses within a hospice $(n=63 ; 61 \%)$. Their mean work experience was of 17.9 years $(\mathrm{SD}=11.0)$ as nurses and 6.8 years $(\mathrm{SD}=5.2)$ as palliative care nurses. 


\section{Correlations among study variables}

Table 2 shows scores and correlations among study variables. Participants reported high levels of professional competency in all of the five dimensions, especially in their ability to take care of each person, with sensitivity and attention in a comprehensive, tolerant, and non-judgmental manner. Their JS was high. Participants reported to frequently engage in $\mathrm{OCB}$, showing in particular high conscientiousness. Overall, all of the study variables were positively correlated with each other. The more palliative care nurses believed to be professionally competent, the more they were satisfied with their job and engaged in OCB, and viceversa. Greater JS was also associated with higher OCB.

\section{The hypothesised model}

The model tested fitted the data well: $\chi^{2}(\mathrm{df}=25, \mathrm{~N}=107)=33.50 \mathrm{p}=0.12, \mathrm{CFI}=0.98$, TLI $=0.97$, RMSEA $=$ $0.06(90 \% \mathrm{CI}=0.00-0.10) \mathrm{p}=0.39, \mathrm{SRMR}=0.04($ Fig 1$)$. Perceived professional competency positively influenced JS ( $\beta=0.39$ ) and OCB ( $\beta=0.53$ ). The more participants believed to practice their profession in accordance with ethical principles, to personalise care, to remain sensitive, to ensure respect, and to communicate effectively, the more they were satisfied with their job and engaged in OCB. 


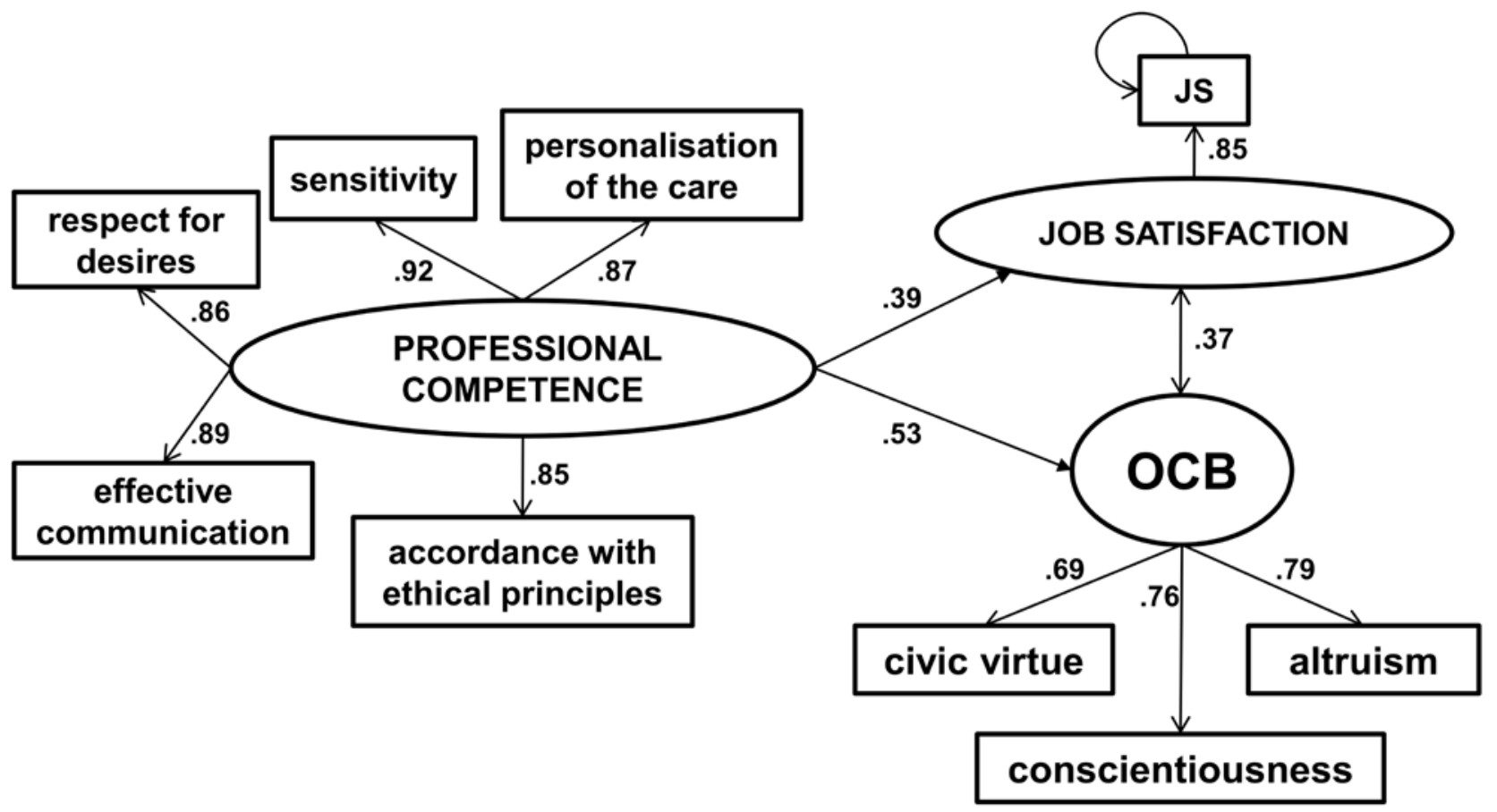

Figure 1. The role of perceived professional competencies in predicting job satisfaction and organizational citizenship behaviour.

\section{DISCUSSION}

This study highlighted the importance of the perception of high professional competency among palliative care nurses. Caring for patients during their end-of-life period can represent a challenge at different levels, especially when specific education is lacking (Martins Pereira \& Hernandez-Marrero, 2016), thereby nurses may feel unprepared and lack the necessary confidence (Henderson et al., 2016). In this study, however, nurses reported high professional competency in taking care of each person with sensitivity and attention in a comprehensive, tolerant and non-judging manner. This is a core competency in palliative care, as patients and their families wish to receive end-of-life care from health professionals able to be present, reassuring, and honouring choices (Ciemins et al., 2015).

In order to ensure high quality patient care and achieve positive organisational outcomes, palliative care nurses should develop specific competencies, such as practicing their profession in accordance with ethical principles, personalising care, remaining sensitive, ensuring respect, and communicating effectively, but also perceive themselves as effective in implementing those competencies (Bandura, 1997). In particular, 
this study showed that the more nurses were confident about being professionally competent, the more they were satisfied with their job and engaged in OCB. The first finding of this study suggests that nurses' JS is influenced by the level of their perceived competency. This is in line with previous studies reporting positive associations between JS and self-efficacy (Bryant-Lukosius et al., 2007; DeLoach \& Monroe, 2004; Sand et al., 2017). Indeed, nurses who report more professional competency can show higher confidence in performing their job activities, feel more prepared and adequate, and thereby consider their job easier, less demanding, and more rewarding. Since several factors can hamper nurses' JS, such as hard task requirements, strict organizational policies, and poor career progression (Sansoni et al., 2016), it is crucial to empower nurses by promoting and recognising their professional competency. Strategies to enhance nursing competency includes improving theoretical knowledge, promoting professional understanding, fostering reflection, and developing specific attitudes (Sand et al., 2017; Mastroianni et al., 2015). Nurses' self-competence can be also enhanced by a supportive organisation that cares about their well-being and fosters their work commitment (Battistelli et al., 2016).

The second finding of this study revealed that nurses with higher perceived competency have greater inner resources to perform their work conscientiously, participate in organisational life, and engage in altruistic behaviour towards colleagues (OCB). This seems reasonable as health professionals who believe to be highly competent in their work activity could translate that belief into a desire to help colleagues and/or their organisation, motivated by their high work engagement (Salanova et al., 2011). Our results agree with scholars (Bandura et al., 2003; Bandura et al., 2001; Staub, 2013) suggesting that self-efficacy beliefs exert a protective role in contrasting antisocial behaviors and in promoting prosocial behaviors. Findings are also in line with research in the work setting arguing that the convictions of success are likely to support the workers' spontaneous initiative to engage in actions beyond what is formally expected (Speier \& Frese, 1997; Somech \& Drach-Zahavy, 2000). Thus, prosocial behaviour at work might be associated not only with personal characteristics, such as prosociality (Biagioli et al., 2016), or contextual factors, such as a compassionate and caring organisational culture (Chu, 2016), but also with higher self-competence. Therefore, fostering the development and the perception of nurses' professional competency can be 
beneficial to the nurses themselves, as they can experience a greater JS; to their colleagues, who can receive help through altruistic behaviour; and to their organisation, as civic virtue is cultivated.

\section{Limits}

This study is not without limitations. The small sample size might reduce the validity of the findings and limit the representativeness of the sample, as nurses with higher resources are more likely to participate in research studies. Another limitation is the possibility of the social desirability bias, with participants reporting higher values then real to appear more competent and professionally engaged. In addition, crosssectional data may limit the causal directions of the model tested. Bidirectional associations are also possible: nurses who help their co-workers during their job might get, in turn, an improved self-concept. Future studies should examine the predictive role of professional competency over time.

\section{CONCLUSIONS}

This study confirmed the hypothesis that the more nurses believe in their professional competency, the more they are satisfied with their job and show altruism, civic virtue, and conscientiousness (OCB). Since delivery of high quality palliative care depends on the competency of health professionals and a supportive work environment, it is crucial for health organisations to empower palliative care nurses. One of the best way to empower nurses is to enhance their beliefs in their professional competency, which in turn will contribute to improve their JS and extra-role performance, resulting in benefit for the nurses themselves, the organisation, and their co-workers. It is relevant to understand how palliative services may better help their employees in enhancing their beliefs about the different professional competencies, creating a sense of professional agency for the management of end-of-life situations and building a more resilient work environment. Palliative services able to promote nurses' self-competence in caring for patients during their end-of-life are likely to attract and retain staff and improve patients' and workers' satisfaction, safety, and outcomes, while delivering cost-effective services. 


\section{REFERENCES}

Argentero, P., Cortese, C.G. \& Ferretti, M.S. (2008). An evaluation of organizational citizenship behavior: Psychometric characteristics of the Italian version of Podsakoff et al.'s scale. Testing, Psicometria, Metodologia, 15(2), 61-75.

Bandura, A. (1997). Self-efficacy: The exercise of control, New York, NY: Freeman.

Bandura, A., Caprara, G.V., Barbaranelli, C., Gerbino, M. \& Pastorelli, C. (2003). Role of affective selfregulatory efficacy in diverse spheres of psychosocial functioning. Child Development, 74(3), 769-782.

Bandura, A., Caprara, G.V., Barbaranelli, C., Pastorelli, C. \& Regalia, C. (2001). Sociocognitive self-regulatory mechanisms governing transgressive behavior. Journal of Personality and Social Psychology, 80(1), 125135.

Battistelli, A., Galletta, M., Vandenberghe, C. \& Odoardi, C. (2016). Perceived organisational support, organisational commitment and self-competence among nurses: A study in two Italian hospitals. Journal of Nursing Management, 24(1), E44-E53.

Becker, R. (2009). Palliative care. 2: Exploring the skills that nurses need to deliver high-quality care. Nursing Times, 105(14), 18-20.

Biagioli, V., Prandi, C., Giuliani, L., Nyatanga, B. \& Fida, R. (2016). Prosocial behaviour in palliative nurses: Psychometric evaluation of the prosociality scale. International Journal of Palliative Nursing, 22(6), 292298.

Bryant-Lukosius, D., Green, E., Fitch, M., Macartney, G., Robb-Blenderman, L., McFarlane, S., Bosompra, K., DiCenso, A., Matthews, S. \& Milne, H. (2007). A survey of oncology advanced practice nurses in Ontario: Profile and predictors of job satisfaction. Nursing Leadership, 20(2), 50-68.

Caricati, L., Sala, R.L., Marletta, G., Pelosi, G., Ampollini, M., Fabbri, A., Ricchi, A., Scardino, M., Artioli, G. \& Mancini, T. (2014). Work climate, work values and professional commitment as predictors of job satisfaction in nurses. Journal of Nursing Management, 22(8), 984-994.

Caruso, R., Fida, R., Sili, A. \& Arrigoni, C. (2016). Towards an integrated model of nursing competence: An overview of the literature reviews and concept analysis. Professioni Infermieristiche, 69(1), 35-43. 
Chen, C.-H.V. \& Kao, R.-H. (2011). A multilevel study on the relationships between work characteristics, self-efficacy, collective efficacy, and organizational citizenship behavior: The case of Taiwanese police duty-executing organizations. The Journal of Psychology, 145(4), 361-390.

Chu, L.C. (2016). Mediating positive moods: The impact of experiencing compassion at work. Journal of Nursing Management, 24(1), 59-69.

Cicolini, G., Comparcini, D. \& Simonetti, V. (2014). Workplace empowerment and nurses' job satisfaction: A systematic literature review. Journal of Nursing Management, 22(7), 855-871.

Ciemins, E.L., Brant, J., Kersten, D., Mullette, E. \& Dickerson, D. (2015). A qualitative analysis of patient and family perspectives of palliative care. Journal of Palliative Medicine, 18(3), 282-285.

Clark, J.E., Aitken, S., Watson, N., McVey, J., Helbert, J., Wraith, A., Taylor, V. \& Catesby, S. (2015). Training oncology and palliative care clinical nurse specialists in psychological skills: Evaluation of a pilot study. Palliative \& Supportive Care, 13(3), 537-542.

DeLoach, R. \& Monroe, J. (2004). Job satisfaction among hospice workers: What managers need to know. The Health Care Manager, 23(3), 209-219.

Desbiens, J.F., Gagnon, J. \& Fillion, L. (2012). Development of a shared theory in palliative care to enhance nursing competence. Journal of Advanced Nursing, 68(9), 2113-2124.

Fernandez, N., Dory, V., Ste-Marie, L.G., Chaput, M., Charlin, B. \& Boucher, A. (2012). Varying conceptions of competence: An analysis of how health sciences educators define competence. Medical Education, 46(4), 357-365.

Fillion, L., Duval, S., Dumont, S., Gagnon, P., Tremblay, I., Bairati, I. \& Breitbart, W.S. (2009). Impact of a meaning-centered intervention on job satisfaction and on quality of life among palliative care nurses. Psycho-Oncology, 18(12), 1300-1310.

Galletta, M., Portoghese, I., Carta, M.G., D'Aloja, E. \& Campagna, M. (2016). The effect of nurse-physician collaboration on job satisfaction, team commitment, and turnover intention in nurses. Research in Nursing $\mathcal{E}$ Health, 39(5), 375-385. 
Gamondi, C., Larkin, P. \& Payne, S. (2013). Core competencies in palliative care: An EAPC white paper on palliative care education: part 1. European Journal of Palliative Care, 20(2), 86-91.

Greenslade, J. \& Jimmieson, N. (2011). Organizational factors impacting on patient satisfaction: A cross sectional examination of service climate and linkages to nurses' effort and performance. International Journal of Nursing Studies, 48(10), 1188-1198.

Greenslade, J.H. \& Jimmieson, N.L. (2007). Distinguishing between task and contextual performance for nurses: Development of a job performance scale. Journal of Advanced Nursing, 58(6), 602-611.

Henderson, A., Rowe, J., Watson, K. \& Hitchen-Holmes, D. (2016). Graduating nurses' self-efficacy in palliative care practice: An exploratory study. Nurse Education Today, 39, 141-146.

Hu, L.-t. \& Bentler, P.M. (1999). Cutoff criteria for fit indexes in covariance structure analysis: Conventional criteria versus new alternatives. Structural Equation Modeling, 6(1), 1-55.

Ko, Y.K. (2008). Identification of factors related to hospital nurses' organizational citizenship behavior using a multilevel analysis. Journal of Korean Academy of Nursing, 38(2), 287-297.

Locke, E.A. (1976). The nature and causes of job satisfaction. In Handbook of industrial and organizational psychology, Dunnette, M. (ed.), pp. 1297-1343. Chicago: Rand McNally.

Martins Pereira, S. \& Hernandez-Marrero, P. (2016). Palliative care nursing education features more prominently in 2015 than 2005: Results from a nationwide survey and qualitative analysis of curricula. Palliative Medicine, 30(9), 884-888.

Mastroianni, C., Piredda, M., Taboga, C., Mirabella, F., Marfoli, E., Casale, G., Matarese, M., Frommelt, K.H. \& De Marinis, M.G. (2015). Frommelt Attitudes Toward Care of the Dying Scale Form B: Psychometric testing of the Italian version for students. Omega, 70(3), 227-250.

Muthén, L. \& Muthén, B. (1998-2017). Mplus user's guide, Los Angeles, CA: Muthén \& Muthén.

Organ, D.W. (1988). Organizational citizenship behavior: The good soldier syndrome, Lexington, MA: Lexington Books DC Heath.

Parry, S.B. (1996). The quest for competencies. Training, 33(7), 48-56. 
Petitta, L., Borgogni, L., Mastrorilli, A. \& Scarpa, A. (2004). Organizational citizenship behavior ed efficacia dell'organizzazione. Bollettino di Psicologia Applicata, 243, 15-30.

Podsakoff, N.P., Whiting, S.W., Podsakoff, P.M. \& Blume, B.D. (2009). Individual-and organizational-level consequences of organizational citizenship behaviors: A meta-analysis. The Journal of Applied Psychology, 94(1), 122-141.

Podsakoff, P.M., MacKenzie, S.B., Moorman, R.H. \& Fetter, R. (1990). Transformational leader behaviors and their effects on followers' trust in leader, satisfaction, and organizational citizenship behaviors. The Leadership Quarterly, 1(2), 107-142.

Prandi, C., Biagioli, V. \& Fida, R. (2015). Self-assessment of palliative nurses' competencies: A preliminary study on the validity of the questionnaire Professional Competence of the Core Curriculum in Palliative Care Nursing (CCICP) Rivista Italiana di Cure Palliative, 17(3), 1-11.

Qaseem, B., Shea, J., Connor, S.R. \& Casarett, D. (2007). How well are we supporting hospice staff? Initial results of the survey of team attitudes and relationships (STAR) validation study. Journal of Pain and Symptom Management, 34(4), 350-358.

Reville, B. \& Foxwell, A.M. (2017). Competency milestones: Guidelines for advanced practice palliative nurses. Journal of Hospice \& Palliative Nursing, 19(4), 339-342.

Salanova, M., Lorente, L., Chambel, M.J. \& Martínez, I.M. (2011). Linking transformational leadership to nurses' extra-role performance: The mediating role of self-efficacy and work engagement. Journal of Advanced Nursing, 67(10), 2256-2266.

Sand, L., Olsson, M. \& Strang, P. (2017). Supporting in an existential crisis: A mixed-methods evaluation of a training model in palliative care. Palliative \& Supportive Care, 1-9.

Sansoni, J., De Caro, W., Marucci, A.R., Sorrentino, M., Mayner, L. \& Lancia, L. (2016). Nurses' job satisfaction: An Italian study. Annali di Igiene, 28(1), 58-69.

SICP. (2013). Il core curriculum dell'infermiere in cure palliative. http://www.sicp.it/web/procedure/contenuto.cfm?List=WsPageNameCaller,WsIdEvento,WsIdRispo 
sta,WsRelease\&c1=\%2Fweb\%2Feventi\%2FSICP\%2Fcorecurriculum\%2Ecfm\%3FList $\% 3$ DWsStartRow $\% 26 c 1 \% 3$ D $1 \& c 2=$ CORECUSICP\&c3 $=4 \& c 4=1$

Slatten, K., Hatlevik, O. \& Fagerstrom, L. (2014). Validation of a new instrument for self-assessment of nurses' core competencies in palliative care. Nursing Research and Practice, 2014, 615498.

Smith, P.C., Kendall, L.M. \& Hulin, C.L. (1969). The measurement of satisfaction in work and retirement, Chicago: Rand McNally.

Somech, A. \& Drach-Zahavy, A. (2000). Understanding extra-role behavior in schools: The relationships between job satisfaction, sense of efficacy, and teachers' extra-role behavior. Teaching and Teacher Education, 16(5), 649-659.

Speier, C. \& Frese, M. (1997). Generalized self efficacy as a mediator and moderator between control and complexity at work and personal initiative: A longitudinal field study in East Germany. Human Performance, 10(2), 171-192.

Staub, E. (2013). Development and maintenance of prosocial behavior: International perspectives on positive morality, New York and London: Plenum Press.

Todd, S.Y. \& Kent, A. (2006). Direct and indirect effects of task characteristics on organizational citizenship behavior. North American Journal of Psychology, 8(2), 253-268.

Walumbwa, F.O., Hartnell, C.A. \& Oke, A. (2010). Servant leadership, procedural justice climate, service climate, employee attitudes, and organizational citizenship behavior: A cross-level investigation. Journal of Applied Psychology, 95(3), 517-529.

Zaghini, F., Biagioli, V., Prandi, C., Fida, R. \& Sili, A. (2015). Nurses and organizational citizenship behavior: Contribution to the Italian validation of the Podsakoff et al. scale. La Medicina del Lavoro, 106(6), 460471. 
Table 1. The five competencies of the core curriculum in palliative nursing rated as the most important by experts.

1 Ability to practice the nursing profession in accordance with ethical, deontological, and legal principles, recognising and addressing, as a team, the ethical $\backslash$ moral issues and the clinical situations that are difficult and controversial.

2 Ability to personalise the care to improve the quality of life of the patient and his/her family, relieving the physical, psychosocial, and spiritual suffering, as a team and across all of the services of the palliative network.

3 Ability to take care of each person, with sensitivity and attention in a comprehensive, tolerant, and nonjudgmental manner.

4 Ability to take care of the patient and his/her family, ensuring respect for their rights, their beliefs, their system of values and their desires.

5 Ability to communicate effectively with the patient and with his/her family, even in cases where the patient show deterioration of verbal and/or nonverbal communication.

Table 2. Descriptive statistics and correlations among perceived competency, job satisfaction, and organizational citizenship behavior.

\begin{tabular}{|c|c|c|c|c|c|c|c|c|c|c|c|}
\hline Variable & Mean & SD & 1 & 2 & 3 & 4 & 5 & 6 & 7 & 8 & 9 \\
\hline 1. Competency 1 & 8.04 & 1.34 & $(.93)$ & & & & & & & & \\
\hline 2. Competency 2 & 7.95 & 1.01 & $.79^{* * * *}$ & $(.87)$ & & & & & & & \\
\hline 3. Competency 3 & 8.28 & 1.09 & $.78^{* * *}$ & $.82^{* * *}$ & $(.92)$ & & & & & & \\
\hline 4. Competency 4 & 7.82 & 1.26 & $.70^{* * * *}$ & $.71^{* * *}$ & $.78^{* * *}$ & $(.84)$ & & & & & \\
\hline 5. Competency 5 & 7.86 & 1.14 & $.76^{* * * *}$ & $.74^{* * *}$ & $.81^{* * *}$ & $.83^{* * * *}$ & $(.91)$ & & & & \\
\hline 6. Job satisfaction & 15.14 & 2.44 & $.23^{*}$ & $.30^{* *}$ & $.36^{* * *}$ & $.26^{* *}$ & $.27^{* *}$ & $(.72)$ & & & \\
\hline 7. Conscientiousness & 4.32 & 0.49 & $.31^{* * *}$ & $.29^{* *}$ & $.29^{* *+}$ & $.36^{* *+*}$ & $.29^{* *}$ & $.29^{* *}$ & $(.63)$ & & \\
\hline 8. Altruism & 4.22 & 0.53 & $.41^{* * *}$ & $.39^{* * *}$ & $.39^{* * *}$ & $.36^{* * *}$ & $.34^{* * *}$ & $.28^{* *}$ & $.64^{* * *}$ & $(.82)$ & \\
\hline 9. Civic virtue & 3.89 & 0.70 & $.33^{* * * *}$ & $.42^{* * *}$ & $.39^{* * *}$ & $.36^{* * *}$ & $.37^{* * * *}$ & $.41^{* * *}$ & $.52^{* * *}$ & $.52^{* * *}$ & $(.78)$ \\
\hline
\end{tabular}

Note: The five competencies are presented in Table 1; Cronbach's alpha is shown on diagonal in brackets; ${ }^{*} \mathrm{p}<.05 ;{ }^{* *} \mathrm{p}<.01 ; * * * \mathrm{p}<.001$ 